\title{
Protection Analysis for Plant Rating and Power Quality Issues in LVDC Distribution Power Systems
}

\author{
Abdullah Emhemed \\ EEE, University of Strathclyde \\ Glasgow, UK \\ Abdullah.emhemed@strath.ac.uk
}

\author{
Graeme Burt \\ EEE, University of Strathclyde \\ Glasgow, UK \\ Graeme.burt@strath.ac.uk
}

\begin{abstract}
Low Voltage DC (LVDC) distribution systems have the potential to be considered as an efficient platform for facilitating the connection of more distributed energy resources. The applications of LVDC are still at an early stage due to the lack of mature experience and standards. Over and above, the protection challenges that are presented by integrating DC installations in existing $\mathrm{AC}$ systems are one of the key issues that are delaying the wide uptake of LVDC technologies. In response to these issues, this paper discusses the international installation progress of LVDC systems and their relevant standards in different sectors. This includes data centres, buildings, and utility last mile distribution systems. The paper also investigates the impact of using traditional LV protection methods on the performance of a faulted LVDC network, and on the associated post-fault power quality performance. A typical UK LV network is energised using DC and modelled in PSCAD, and used for the protection studies under different DC fault conditions.
\end{abstract}

Index Terms-- Distributed energy resources, Low Voltage Direct Current (LVDC) distribution systems, power system protection, power quality, and smart grid.

\section{INTRODUCTION}

The growing awareness towards the environment, and the pressure for decarbonising energy systems have led to a significant change in the nature of traditional distribution systems [1]. This involves the connection of more small scale renewables, the deployment of demand side controls, and the electrification of more heat and transport demands. Such changes will lead to the requirement for the provision of significantly increased power capacity and the integration of more decentralised controls. The issue is that most of existing distribution systems are very old, and already designed and operated close to their operating limits. Using traditional reinforcement solutions to increase the power capacity for addressing the aforementioned changes will be very expensive, slow, and power interruptive. Therefore, LVDC distribution systems with help of advanced power electronics and information communication technologies (ICT) have the potential to be used as an alternative measure to improve the efficiency and cable capacities of existing distribution networks in more effective way [2]-[3]. The motivation is that

This work was supported by the RCUK's Energy Programme as part of the Top \& Tail Transformation programme (grant EP/I031707/1). most of decentralised renewables such as photovoltaic, fuel cells, batteries, and variable frequency sources generate DC or require DC intermediate stages. Such sources can be connected directly to DC systems and more energy losses can be reduced. In addition, advanced power electronics in LVDC will offer better controllability of the sources and demand congestion, resulting in a higher power capacity that is required for accommodating the forecasted growth in demand. A number of studies as reported in [4] and under different operating assumptions have already stated that LVDC systems can deliver energy savings from $2 \%-14 \%$ compared to the AC.

Moving from $\mathrm{AC}$ to $\mathrm{DC}$ distribution systems is very challenging. Integrating LVDC systems within existing AC grids will present significant technical challenges for operating and protecting the new hybrid system. Among other operating challenges, LVDC protection is one of the key area that needs to be considered [4]. This is because most of existing traditional LV protection systems have been designed for AC with limited protection capabilities. When LVDC systems are used, and under faulted conditions, aggressive forms of DC faults with different fault transients will be introduced. Therefore, addressing LVDC protection issues is significantly important by which the risk of improper moves to DC can be reduced, and a new design of reliable DC protection systems can be proposed.

This paper discusses the development of LVDC and their progress to date in different distribution system applications, and it focuses more on the analysis of an LVDC last mile distribution network under faulted conditions. The paper provides the following contributions: Section II investigates the potential benefits of LVDC implementations and their installation sizes in different fields. This includes data and telecommunication centres, installation in buildings, and last mile public distribution networks. Section III discusses the potential impact of LVDC deployment on traditional LV protection for safety and equipment. In Section IV, a typical UK LVDC last mile distribution network is modelled, and it is used for investigating the impact of DC faults at different locations on the LVDC last mile protection performance. Finally, the conclusions of the presented work are drawn in section $\mathrm{V}$. 


\section{GROWTH OF LVDC DISTRIBUTION SYSTEMS}

An LVDC distribution system was introduced in 1882 as the first main supply of electricity to customers (Edison's Pearl Street Station) [6]. Since that time, AC has dominated due to the capability of AC for transmitting power over long distances, and LVDC applications have been limited to only specific industrial applications. This includes auxiliary installations in power plants and substations, some emergency services such as lightings and alarms, and traction systems. In today's digital era, the use of electronic devices run on DC and microgenerators generate $\mathrm{DC}$ has been rapidly growing. This (in addition to advanced power electronics) has motivated the return of LVDC distribution systems to be used for powering different sized data centers, facilitating the connection of end-users' electronic loads and sources, and potentially to be used in last mile cables to reduce losses and increase power capacity. This section of the paper discusses the potential benefits and recent applications of LVDC in the following three sectors: data centres, installations in buildings, and last mile (utility) distribution networks.

\section{A. LVDC in Data Centres}

The energy usage in data centres represents $25-60 \%$ of the total operating costs [7]. Using LVDC for powering data centers is very promising to reduce this cost by reducing the AC-DC conversion losses and hence the energy required for cooling IT equipment. The main loads in data centers are computing and IT equipment, and they are inherently run on DC and can be supplied directly by DC. Also most of these loads are identical, and they will not require complex LVDC supplies and different levels of DC-DC converters [7]. LVDC also eliminates the use of DC-AC inverters in uninterruptible power supplies (UPS) and the need for power factor correction unites. The research in [4] has reported that DC UPS costs are 10-20\% lower than AC UPS. A new LVDC 380Vdc standard has been already provided by the open industry association EMerge Alliance [8][9]. The $380 \mathrm{Vdc}$ has been internationally adopted and validated for a number of data centres across the world as shown in in Fig. 1. ABB has reported that the $1 \mathrm{MW}$ 380 V DC network which was built in 2012 to supply a medium sized data centre was $10 \%$ less than the AC system in terms of capital costs [9].

\section{B. LVDC in Buildings}

There are two main market drivers for using LVDC in buildings. One is that almost $80 \%$ of the total loads in commercial and residential premises are DC [10]. Inherently, LVDC is more suitable to directly power these loads and host DC sources and storage. This will reduce losses and harmonics distortion and their associated overheating.

The other factor is that modern DC-DC converters can provide Extra LVDC (ELVDC) (i.e. $<120 \mathrm{Vdc}$ ripple free) [11] for directly powering electronic devices run on low power DC. This would allow the use of Power over Ethernet (PoE) cables to deliver low DC power and data in one wire. Using PoE technology to deliver DC power will potentially save a large installation costs and facilitate the monitoring and controls of DC devices (such as intelligent LED lighting) within a safer environment. This is particularly important for commercial buildings where a large portion of loads are IT and lights. However, most of existing PoE cables are not originally designed for delivering DC power. A number of standard bodies have considered this issue. IEEE 802.3at PoEP-2009 to provide $30 \mathrm{~W}$ at 48 volts $\mathrm{DC}$ is one example of PoE for DC use, and recently IEEE 802.3bt 4PPoE with higher power rating is proposed [13]. Reference [12] has stated that major of PoE providers have started moving to PoEs for powering lighting and other electronic devices.

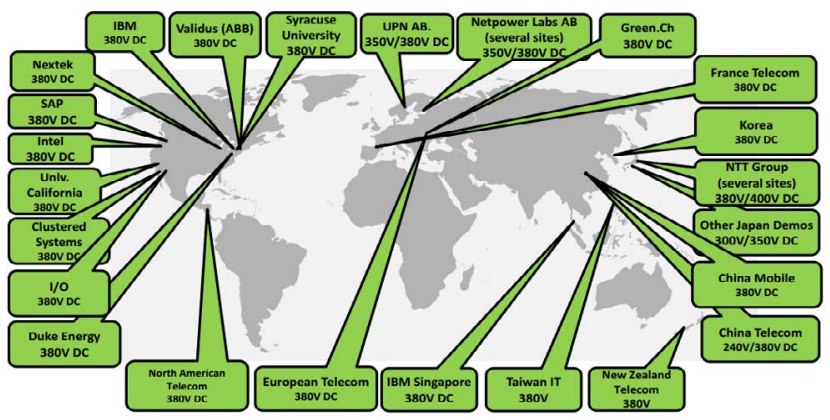

Figure 1. Worldwide LVDC deployments in data centres [14]

\section{LVDC in Last Mile Power Distribution Networks}

The revival of LVDC in last mile public distribution systems is driven by the following advantages:

1) Increased power flow capacity: one option to release more power capacity within existing LVAC cables is by energising the cable using higher DC voltages than existing $400 \mathrm{Vac}$. Most of existing LV cables are rated within the range of $450 \mathrm{~V}-1 \mathrm{kV}$, and LVD 2006/95/EC standard allows the use of LVDC voltages up to $1500 \mathrm{~V}$ [15]. Using LVDC with higher voltages will deliver the same AC power with reduced thermal losses and limited voltage drops in the cables. Also, the inductances effects on voltage profiles will be very limited, and the skin effect issues can be eliminated.

2) Enhanced monitoring and control: LVDC provides better platform for monitoring and controlling DC sources and demands. Only few parameters are required to control and operate the DC network. For example, no frequency control is required, phase balancing is not an issue, and reactive power is less important. Increased controllability and flexibility using DC will also facilitate the stimulation of customers' generation and demand controls, and their contributions to the electricity market.

3) Reduced fault level: the converter interfacing LVDC to the AC grid will reduce the fault levels. This has the potential to facilitate the operation of LV ring configurations, resulting in improved redundancy level, and allow the use of equipment with lower short circuit rating and reduced cost.

The experience from the real rural $\pm 750 \mathrm{~V}$ LVDC test network as reported in [2] has concluded that LVDC is more efficient solution for rural AC networks when the feeder's lengths are over $1 \mathrm{~km}$. LVDC distribution power systems have also been proposed to replace some of the Korea Electric Power Corporation (KEPCO) existing AC rural MV distribution networks (used for supplying light loads) in South 
Korea in order to save up to $5 \%$ of the total operating cost [16].

\section{LVDC Installation Market}

From application size perspectives, LVDC in data centres are leading. As discussed previously, the 380Vdc standard has already achieved energy savings in data centres. LVDC in buildings will come second after the data centres. It is more likely to start with hybrid AC and DC buildings in order to still supply the large number of legacy AC devices, and host the new DC technologies. One issue in relation to DC-based domestic buildings is that no one DC voltage takes control. For example cell phones require $5 \mathrm{~V}$, computers $12 \mathrm{~V}$, LED lighting $24 \mathrm{~V}$, and electrical vehicles $>48 \mathrm{~V}$. But, commercial buildings are different with majority of identical IT and lights, and, they are more likely to lead in terms of LVDC installations in buildings. The Navigant Research Consultant has concluded that DC for commercial buildings will "grow from $\$ 320$ million in annual revenue in 2013 to more than $\$ 2.8$ billion in 2020" [12]. In terms of LVDC in utilities' networks, their application is still very limited. This is due to a significant investment in AC systems, and due to the limited experience that distribution system operators have in LVDC technologies. Recently, there is an international effort to provide technical and regulatory guidance for promoting a greater uptake of LVDC investment. TABLE I gives a number of recent standards that have been developed for different LVDC applications [8] and [17]-[19].

TABLE I. DEVELOPED STANDARDS AsSOCIATED TO LVDC SySTEMS

\begin{tabular}{l|l|c}
\hline & \multicolumn{1}{|c|}{ Standards } & \\
\hline $\begin{array}{l}\text { Data } \\
\text { centres }\end{array}$ & - EMerge Alliance Data/Telecom Centre Standard: & \\
\hline Buildings & 380Vdc & EMerge Alliance Occupied Space Standard: 24Vdc \\
& - IET Code of Practice (CoP) for the application of & \\
& LED lighting systems & \\
& - IET CoP for LVDC power distribution in Buildings" & \\
\hline LVDC & - No standards are available & \\
Last mile & \multicolumn{3}{|c}{ "It will be published in April 2015[17] } \\
\hline \multicolumn{3}{c}{$\begin{array}{l}{ }^{\dagger} \text { A new IEC System Evaluation Group4 (SEG4) has been recently created by the IEC for Low } \\
\text { Voltage Direct Current Applications }\end{array}$}
\end{tabular}

\section{LVDC PROTECTION ISSUES}

This section discusses LVDC protection issues in relation to safety and fault protection.

\section{A. Protection against electric shock and fire}

Basic protection against electric shock (i.e. insulation of live parts, and earthing and equipotential bonding) will be required for DC systems as same as in AC. Therefore, this section discusses only the issues related to fault protection against electric DC shock. This area requires more attention in an LVDC system design. In AC systems, a residual current device (RCD) is used to detect small leakage fault currents, and it trips when a dangerous level of current flows to the earth through a person body. Less sensitive RCDs can also be used to provide protection against fire [20]. The issue with DC systems is that RCDs are not commercially available, and the risk of fire in DC is higher due to the aggression of DC arc [21]. Therefore, further studies and testing are required to investigate the effectiveness of RCDs to detect the leakages in
DC currents. This work is currently investigated by the authors and it will be considered in future publications.

On the other hand, the use of ELV systems in DC will significantly reduce the risk of electric shock. Most of DC loads such as LED lightings, computers, and other DC devices run on low power DC. Using ELVDC systems to supply such devices through power and PoE wires will make electricity in buildings safer than traditional LVAC systems.

\section{B. Protection against DC overcurrent faults}

In general, interrupting a DC overcurrent fault is more difficult than AC. DC current waveforms do not have natural zero crossing points that can correspond to extinguishing the DC arc. However, interrupting a DC current is still possible if current-limiting fuses or current-limiting electro-mechanical CBs such as Moulded Case Circuit Breakers (MCCBs) are used. These devices do not require zero crossing points, but they take longer time to clear DC faults. Using existing LV mechanical breakers for DC protection may lead to the following issues:

- $\quad$ More complex techniques to quench DC arcs such as increased arc lengths by increasing the distance between the contactors and the use of arc splitters are required (i.e. $\mathrm{CB}$ with higher size and weight).

- $\mathrm{DC}$ arc is more aggressive than $\mathrm{AC}$, and the risk of fire and burns is expected in DC systems more than AC. This makes most of MCCBs designed for AC and DC to have lower DC ratings compared to equivalent $\mathrm{AC}$ ratings. For higher $\mathrm{DC}$ ratings, $\mathrm{CBs}$ with multiple poles may be required [22], and this will increase the CB cost and lead to bigger size and weight.

- The tripping characteristics (instantaneous trip unit) of MCCBs need to be adjusted to be applicable to DC systems in order to provide the same sensitivity as in AC systems. The issue is that not all MCCBs have adjustable instantaneous trip units.

The aforementioned DC protection issues are investigated further through modeling of a faulted LVDC system and protection simulation analysis as follows.

\section{AN LVDC MODEL AND PROTECTION STUdIES}

\section{A. Test Network Model}

A typical UK LV last mile distribution network is used as an example to represent the test network, and modelled using PSCAD/EMTDC. The network model is shown as single line diagram in Fig. 2, and it is used to investigate the performance of LVDC under different faulted conditions. Actual data as given in [23] and provided by a UK network operator is used to model the $11 \mathrm{kV}$ medium voltage (MV) AC supply. The MV supply has $\mathrm{X} / \mathrm{R}=5$ and fault level equals to $156 \mathrm{MVA}$ at the ring main unit (RMU). $0.5 \mathrm{MVA} 11 / 0.4 \mathrm{kV}$ transformer with impedance equals to $4.5 \%$ model is used to provide the LV AC voltage.

TABLE II. LVDC NETWORK PARAMETERS

\begin{tabular}{c|c|c|c|l}
\hline DC voltage & $\mathrm{Rdc}$ & $\mathrm{L}$ & $\mathrm{C}($ smoothing $)$ & \\
\hline $750 \mathrm{~V}$ & $0.164(\Omega / \mathrm{km})$ & $0.24(\mathrm{mH} / \mathrm{km})$ & $6750(\mu \mathrm{F})$ & \\
\hline
\end{tabular}




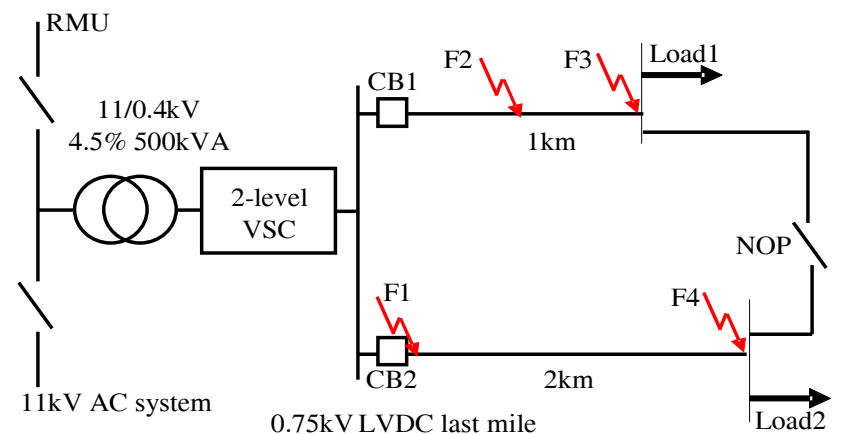

Figure 2. LVDC last mile test distribution network

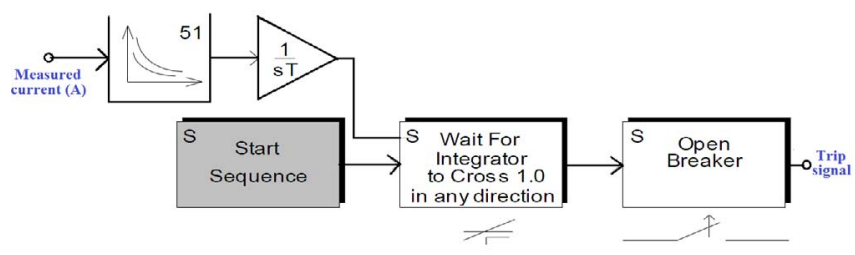

Figure 3. LV overcurrent protection model

The secondary LV substation is interfaced to a radial unearthed unipolar LVDC network by using two-level voltage source converter (VSC). The VSC energises the DC cables by $750 \mathrm{Vdc}$ between the two poles. The converter is fully controlled using the well-known pulse width modulation (PWM) techniques (the required firing signals for the converter's IGBT switches are generated from the generated reference and carrier signals). PI controller is used to correct the error between the actual network voltage and the reference voltage (i.e. $750 \mathrm{Vdc}$ ) by generating the signal for the required angle shift in the reference signal in order to produce the required pulses for the IGBT switches. Two unipolar LVDC cables with different lengths (one is $1 \mathrm{~km}$ and the other is $2 \mathrm{~km}$ ) are connected to the VSC, and modeled using equivalent R-L impedance. The cable's parameters are given in TABLE II, and each cable supplies a lumped $200 \mathrm{kw}$ of load (i.e. $80 \%$ of the transformer capacity at the secondary substation). The loads are modeled as a lump, because the end-users are assumed to be passive and fault investigations are conducted on the utility LVDC cables.

\section{B. LV Protection model}

Each LVDC feeder of the network model is protected by a non-unit overcurrent (OC) protection, and the breaker is added at the beginning of the feeder. This is to evaluate how fast is time-current overcurrent protection (widely used in existing LV) when it is used for protecting an LVDC network. This will have direct impact on the protected system ratings, and on the quality of power. The overcurrent protection is modelled using the extremely inverse time-current characteristic block that is available in PSCAD library. The protection model is presented in Fig. 3. The IEEE Std. C37. 112 curve standard with pickup current equals to twice of the full load current (i.e. $533 \mathrm{~A}$ ) is used within the model to calculate the protection operating times against different fault magnitudes.

\section{Characteristics of DC short-circuit currents}

When a DC fault is initiated, the IGBT switches of the converters are normally blocked for self-protection and the smoothing capacitor of the filters will immediately act as a significant DC source, and feed a high transient current decaying exponentially until the capacitor voltage becomes zero. After the transient is passed, a steady state DC fault current will be supplied by the grid through the antiparallel diodes. A detailed mathematical model and equivalent circuit of a faulted LVDC network are presented by the authors in [3].

\section{DC Faults Simulation Studies}

A short-circuit fault between the positive and negative DC poles is applied at four different locations on the DC feeder as shown in Fig. 2. Fault1 (F1) is applied at the beginning of the feeder, and the other faults F2-F4 are applied at $500 \mathrm{~m}, 1 \mathrm{~km}$, and $2 \mathrm{~km}$ away from the converter terminals respectively. For each DC fault, the protection performance of the faulted feeder is examined, and the post-fault voltages on the adjacent healthy feeder are measured.

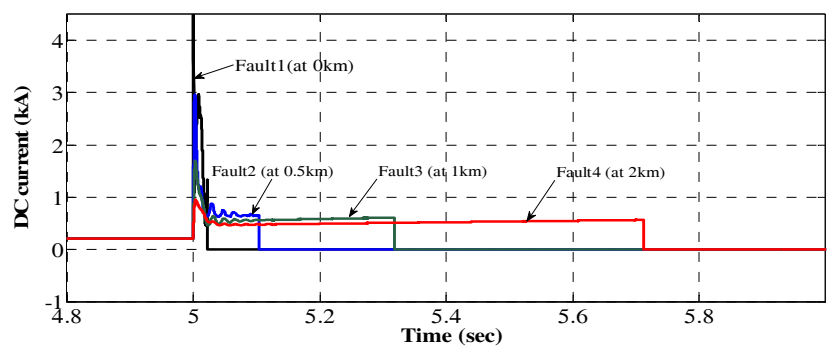

Figure 4. DC fault profiles for faults at different locations and protected by an LV overcurrent protection

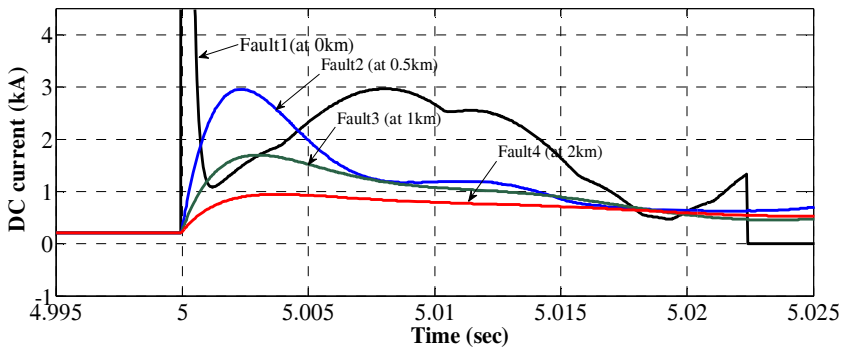

Figure 5. The smoothing capacitor discharging current during DC transient periods for different fault locations

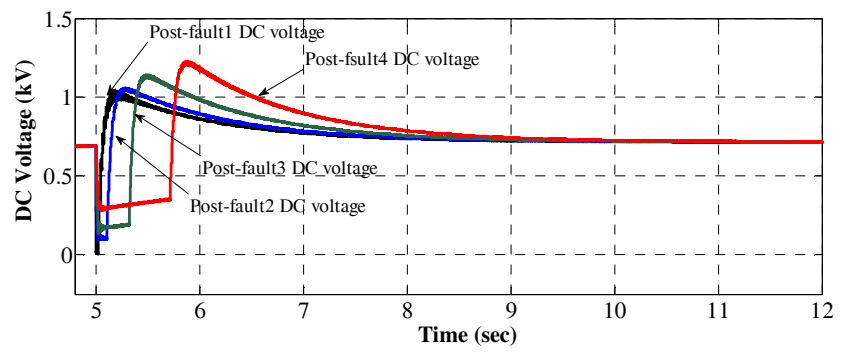

Figure 6. Post-fault DC voltages of the healthy feeder for different fault clearance times 
The simulation results as given in Fig. 4-6 present the following two mains DC protection issues:

1) Plant rating issue due to the pass of high discharging currents: Fig. 4 shows that for all the faults (F1-F4), traditional OC protection is powerless against the high transient DC currents caused by the smoothing capacitor discharging. The operating times are relatively large compared to the required timescale for the discharge $(<4 \mathrm{~ms})$. For the faults close to the converter terminals (F1 and F2) as shown in Fig. 5, the transient discharge currents during the fault reach tens of kAmps. Such high current amplitudes will flow through the network sensitive components with a significant $I^{2} t$ thermal energy, resulting in the requirement for more expensive plant with higher ratings.

2) Power quality issue due to slow performance: Fig. 6 shows that using traditional OC protection has led to a high post-fault transient spikes in the DC voltages on the adjacent healthy feeder. Fault 4 as shown in Fig. 6 (with the largest fault clearance time) has the largest impact on the post-fault DC voltage. The voltage spike reaches up to $200 \%$ of the nominal voltage. This is due the impact of slow protection operating time which allows high energy to be stored in the line reactance during the DC fault. Such performance will impair the quality of power on the unfaulted loads unless surge protection devices are used.

A new technology of mechanical breakers equipped with electronic trip units have been recently developed for an LVDC system protection [22]. The trip times of such breakers are based on embedded curves set within the electronic trip unit. This technology provides programmable trip characteristics, but the DC fault interruption mechanism is still mechanical. It is still hard to clear DC faults during transient periods even with such technologies. One promising technology that can be used to clear DC faults during transient period and within very small timescale is solid state breakers. The authors have developed a new LV multi-function DC protection scheme based on such technologies. More details on the scheme concept is given in [3]. The concept is developed in order to significantly improve LVDC protection operation speed and reduce DC fault stress on the system.

\section{CONCLUSIONS}

LVDC distribution systems have the potential to: fully exploit extra power capacities of existing systems; facilitate more efficient connection of distributed renewables; and deliver enhanced system flexibility for consumers, renewables developers, system service providers, and system operators. The paper has also concluded that using DC overcurrent-time protection schemes based on fuses and mechanical breakers will not provide fast protection that is required to interrupt the DC fault during the transient period. Such slow protection acting will make the system to experience longer short circuit stress and the converters to be defenceless against high transient DC faults. This will increase the requirement for more expensive equipment with higher current ratings, and create power quality issues by generating high post-fault transient voltages on the healthy feeders.

\section{REFERENCES}

[1] C. J. Mozina,"Impact of Smart Grids and Green Power Generation on Distribution Systems," IEEE Trans. Industry Application, vol. 49, no.3, pp.1079-1090, May/Jun. 2013.

[2] T. Kaipia, P. Nuutinen, J. Lohjala, and M. Matikianen, "Field test environment for LVDC distribution - implementation experiences," CIRED Workshop, Lisbon, 29-30 May 2012.

[3] A. Emhemed, and G. Burt, "An Advanced Protection Scheme for Enabling an LVDC Last Mile Distribution Network", IEEE Trans. Smart Grid, vol. 5, no. 5, pp. 2602-2609, Sep. 2014.

[4] M. A. V. Evans, "Why Low Voltage Direct Current Grids?," MSc. Dissertation, Uni. TUDelft, 2013.

[5] S. Fletcher, P. Norman, K. Fong, S. Galloway, and G. Burt, "HighSpeed Differential Protection for Smart DC Distribution Systems," IEEE Trans. Smart Grid, vol. 5, no. 5, pp. 2610-2617, Sep. 2014.

[6] C. Sulzberger, "Thomas Edison's 1882 Pearl Street Generating Station", Available IEEE Global History Network web site: http://www.ieeeghn.org

[7] Discussion Report, "Data Centres and Power: Fact or Fiction", TechUK. London UK, Aug. 2013, Available: https://www.techuk.org/insights/reports/item/275-data-centres-andpower-fact-or-fiction

[8] EMerge Alliance Data/Telecom Center Standard, Available: http://www.emergealliance.org/Standards/OurStandards.aspx

[9] G. AlLee and W. Tschudi, "Edison Redux: 380 Vdc Brings Reliability and Efficiency to Sustainable Data Centres," IEEE Power and Energy Magazine, vol. 10, no. 6, pp. 50-59, Nov/Dec. 2012.

[10] Press release (24 Jun. 2013), "Direct Current Distribution Networks Will Surpass 2.3 Gigawatts in Worldwide Capacity by 2025," Navigant Research, available: http://www.navigantresearch.com/newsroom/

[11] Paul Cook, Commentary on IEE Wiring Redulations $16^{\text {th }}$ Edition BS 7671:2001: Requirements for electrical installations including Amendment No.1:2002, Stevenage: The Institution of Electrical Engineers, 2002, p. 7.

[12] Press release (20 Feb. 2014), "Direct Current Power Supply Equipment for Commercial Buildings Will Reach \$2.8 Billion in Annual Revenue by 2020," Navigant Research, available: http://www.navigantresearch.com/newsroom/

[13] IEEE Standard Association, IEEE Standard for Ethernet Amendment: Physical Layer and Management Parameters for DTE Power via MDI over 4-Pair, IEEE 802.3bt ${ }^{\mathrm{TM}}$ online: http://standards.ieee.org/develop/project/802.3bt.html

[14] D. Geary, D. Mohr, D. Owen, M. Salato, and BJ Sonnenberg "380V DC eco-system development: present status and future challenges," 35th International Telecommunications Energy Conference 'Smart Power and Efficiency' (INTELEC), pp. 224-229, Hamburg, Germany, 13-17 Oct. 2013.

[15] Low Voltage Directive (LVD): EU LV Legislation LVD2006/95/EC, Dec. 2006.

[16] D. Afamefuna, I. Chung, D. Hur, J. Kim, and J. Cho, "A TechnoEconomic Feasibility Analysis on LVDC Distribution System for Rural Electrification in South Korea," Journal of Electrical Engineering \& Technology, vol. 9, pp. 742-751, Apr. 2014.

[17] DPC for Code of Practice for Low and Extra Low Voltage Direct Current Power Distribution in Buildings, www.theiet.org/dc-cop

[18] Code of Practice for the Application of LED Lighting, IET Std. ISBN: 978-1-84919-719-9, 2013.

[19] EMerge Alliance Occupied Space Standard: 24Vdc, Available: http://www.emergealliance.org/Standards/OurStandards.aspx

[20] "The RCD Handbook BEAMA Guide to the Selection and Application of Residual Current Devices," Beama, Sep. 2010.

[21] R. Pinnock, "Protection and Switching in Low Voltage Smart DC Grids," The KTN and IET Forum: DC Energy Systems conference, London, 22 May 2014.

[22] Technical catalogue, "SACE Emax DC Low voltage air circuitbreakers for direct current applications", ABB, Available: http://www05.abb.com/global/scot/scot209.nsf/veritydisplay/297dcb6f4 9ac0ecbc12576d4005b5b32/\$file/1sdc200012d0202.pdf

[23] SP Transmission \& Distribution, Distribution Long Term Development Statement for ScottichPower Distribution LTD-Year 2012-17, 2012. 